\title{
OPEN Temperature induced changes in the optical properties of skin in vivo
}

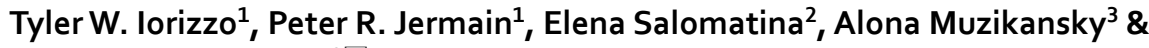 \\ Anna N. Yaroslavsky ${ }^{1,2 \bowtie}$
}

Knowledge of temperature-induced changes of skin optical properties is required for accurate dosimetry of photothermal treatments. We determined and compared in vivo optical properties of mouse ear skin at different temperatures. The diffuse reflectance, total and diffuse transmittance were measured in the spectral range from 400 to $1650 \mathrm{~nm}$ using an integrating sphere spectrometer at the temperatures of $25^{\circ} \mathrm{C}, 36^{\circ} \mathrm{C}$ and $60^{\circ} \mathrm{C}$. Target temperatures were attained and maintained using an automated heater equipped with a sensor for feed-back and control. Temperature and temperature induced morphological changes of skin were monitored using an infrared thermal camera and reflectance confocal microscopy, respectively. An inverse Monte Carlo technique was utilized to determine absorption, scattering, and anisotropy factors from the measured quantities. Our results indicate significant differences between the optical properties of skin at different temperatures. Absorption and scattering coefficients increased, whereas anisotropy factors decreased with increasing temperature. Changes in absorption coefficients indicate deoxygenation of hemoglobin, and a blue shift of water absorption bands. Confocal imaging confirmed that our observations can be explained by temperature induced protein denaturation and blood coagulation. Monitoring spectral responses of treated tissue may become a valuable tool for accurate dosimetry of light treatments.

Therapeutic and surgical applications of light often cause an increase in temperature ${ }^{1-13}$, which may alter the optical properties of target and adjacent organs. Such changes have been reported in several tissues, including adipose $^{14}$, brain $^{15,16}, \operatorname{skin}^{17-19}$, prostate $e^{20}$, and liver ${ }^{21-23}$. Thus, there is a great need to examine dependence of the optical properties on tissue temperature. Several groups investigated the impact of freezing or heating on the ex vivo optical properties ${ }^{14,17,19-23}$. In vivo studies are rare and often restricted to narrow wavelength ranges ${ }^{24-27}$. Yet, quantifying temperature induced changes in optical properties of in vivo tissue would provide a better understanding of tissue response during phototherapy and would ultimately lead to the improvement of light dosimetry. Previously, we have used a mouse ear skin model to examine the differences in the optical constants measured in vivo and ex vivo ${ }^{19}$. The goal of this study was to investigate temperature dependence of the optical properties of skin, in vivo, using integrating sphere measurements combined with inverse Monte Carlo technique, and to monitor heat induced morphological changes to the tissue structure using reflectance confocal microscopy.

\section{Results}

We have determined in vivo absorption coefficients, scattering coefficients, and anisotropy factors of mouse ear tissues at three temperatures of $25^{\circ} \mathrm{C}, 36^{\circ} \mathrm{C}$, and $60^{\circ} \mathrm{C}$. In total, thirty-two sets of data were acquired, processed, and analyzed, including twelve sets at $25^{\circ} \mathrm{C}$, ten sets at $36^{\circ} \mathrm{C}$, and ten sets at $60^{\circ} \mathrm{C}$.

Calculated optical properties. In Fig. 1, the averaged absorption coefficients $\left(\mu_{a}\right)$ in the spectral range between 400 and $1650 \mathrm{~nm}$ are presented. Figure 1a demonstrates that at all the temperatures investigated, absorption of mouse ear tissue is dominated by hemoglobin in the spectral range from 400 to $950 \mathrm{~nm}$ and by water in the spectral range from 1150 to $1650 \mathrm{~nm}$. Wavelength dependence of the absorption coefficients at $25^{\circ} \mathrm{C}$ and at $36^{\circ} \mathrm{C}$ is similar both qualitatively and quantitatively. In contrast, absorption coefficients at $60^{\circ} \mathrm{C}$ are significantly higher than those at the lower temperatures. There are also clearly pronounced spectrally dependent differences.

${ }^{1}$ Advanced Biophotonics Laboratory, University of Massachusetts Lowell, 175 Cabot Street, Lowell, MA 01854, USA. ${ }^{2}$ Department of Dermatology, Massachusetts General Hospital, 50 Staniford Street, Boston, MA 02114, USA. ${ }^{3}$ Biostatistics Center, Massachusetts General Hospital, Boston, MA 02114, USA. ${ }^{\square}$ email: Anna_Yaroslavsky@ uml.edu 


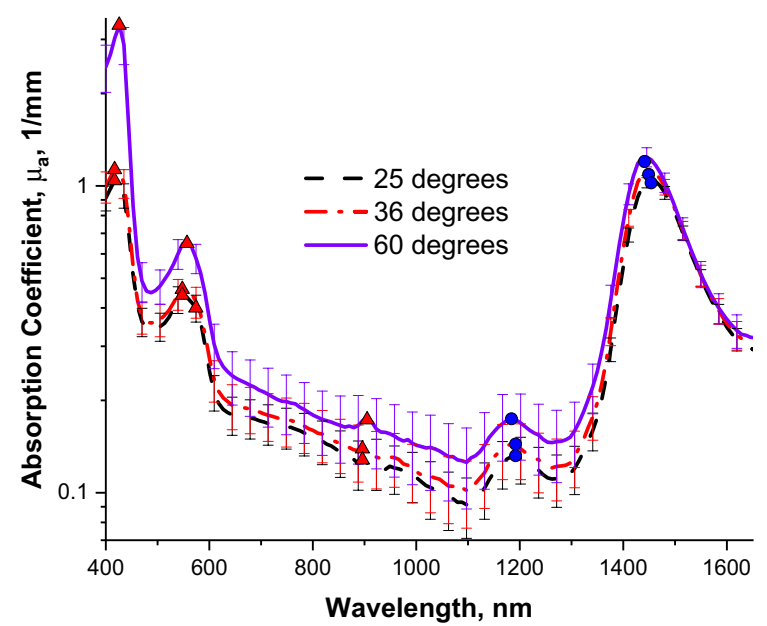

(a)

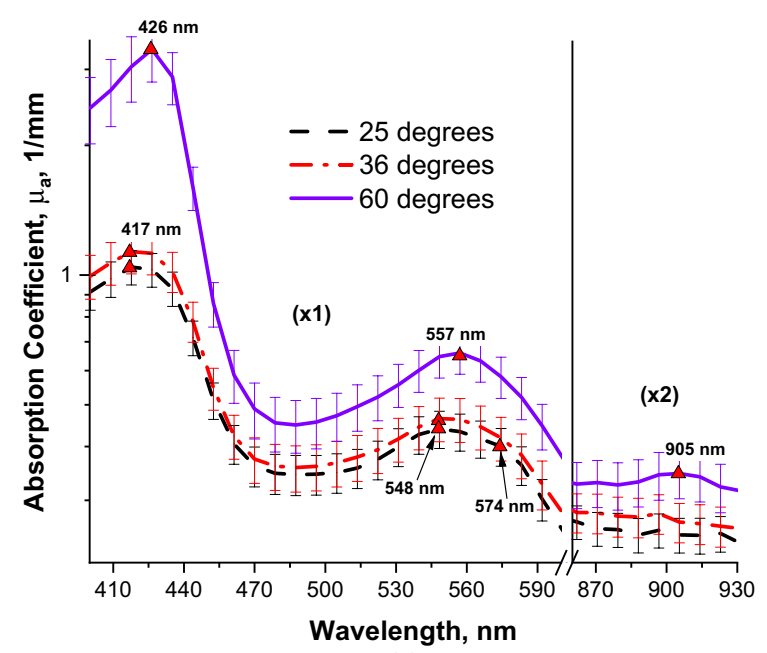

(b)

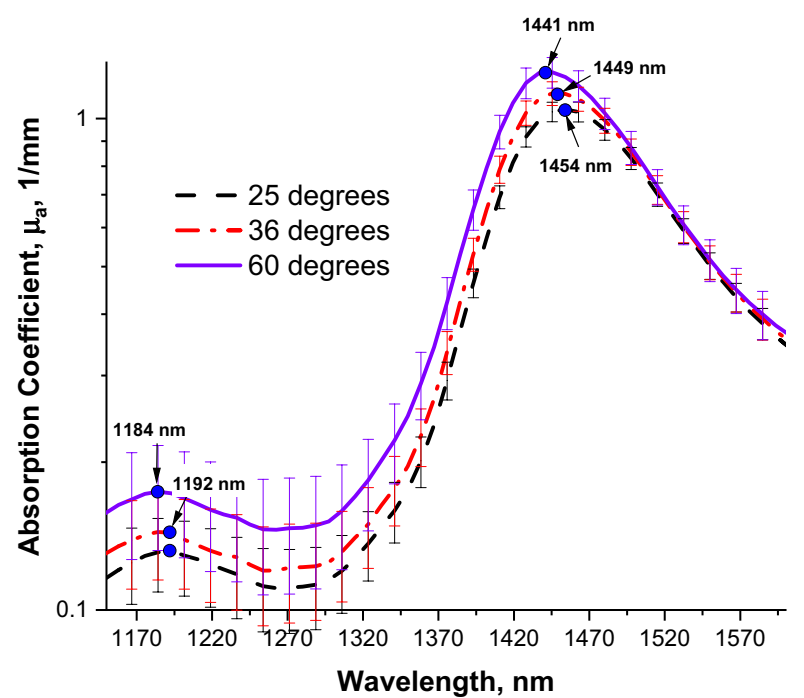

(c)

Figure 1. Absorption coefficients between (a) 400-1650 nm, (b) 400-930 nm (note the scale change in the NIR region), and (c) $1150-1600 \mathrm{~nm}$. Dashes $-25^{\circ} \mathrm{C}$. Dashes and dots $-36^{\circ} \mathrm{C}$. Solid line $-60{ }^{\circ} \mathrm{C}$. Bars-standard errors. Red triangles-maxima of hemoglobin peaks. Blue circles-maxima of water peaks.

Figure $1 \mathrm{~b}$ shows a magnified view of the absorption bands between 400 and $930 \mathrm{~nm}$. It can be readily appreciated that Soret absorption band of hemoglobin exhibits a red shift from $417 \mathrm{~nm}$ at the lower temperatures to $426 \mathrm{~nm}$ 
at $60{ }^{\circ} \mathrm{C}$. Even though ketamine-xylazine anesthetic reduces hemoglobin oxygenation ${ }^{28}$, double absorption peak of oxyhemoglobin between 545 and $575 \mathrm{~nm}$ is discernible at the lower temperatures. It is replaced by a single peak of deoxy-hemoglobin at approximately $557 \mathrm{~nm}$ at $60{ }^{\circ} \mathrm{C}$. In addition, there appears a deoxy-hemoglobin absorption band around $905 \mathrm{~nm}$. Figure 1c displays a magnified view of the absorption bands between 1150 and $1600 \mathrm{~nm}$ with two water absorption peaks in the proximity of $1200 \mathrm{~nm}$ and $1450 \mathrm{~nm}$. Both peaks exhibit considerable blue shifts as tissue temperature increased to $60^{\circ} \mathrm{C}$. Specifically, the water absorption peak shifts from $1192 \mathrm{~nm}$ at $25^{\circ} \mathrm{C}$ and $36^{\circ} \mathrm{C}$ to $1184 \mathrm{~nm}$ at $60^{\circ} \mathrm{C}$, whereas the absorption peak located at $1454 \mathrm{~nm}$ at $25^{\circ} \mathrm{C}$ shifts to $1449 \mathrm{~nm}$ at $36^{\circ} \mathrm{C}$ and to $1441 \mathrm{~nm}$ at $60^{\circ} \mathrm{C}$. Statistical analysis confirmed that the blue shifts in water absorption as temperature increased from 25 to $60^{\circ} \mathrm{C}$ were highly significant $(P<0.0001)$.

Calculated scattering coefficients $\left(\mu_{s}\right)$, anisotropy factors $(\mathrm{g})$, and reduced scattering coefficients $\left(\mu_{s}{ }^{\prime}\right)$, at all the temperatures investigated are shown in Fig. 2. Scattering coefficients (Fig. 2a) were found to decrease with increasing wavelength at each temperature, with stronger spectral dependence at $60^{\circ} \mathrm{C}$, as compared to $25^{\circ} \mathrm{C}$ and $36^{\circ} \mathrm{C}$. A much steeper slope of the scattering coefficient versus wavelength graph at $60^{\circ} \mathrm{C}$ may be explained by tissue coagulation that causes destruction of the larger scatterers, such as erythrocytes, as well as homogenization of the blood vessel walls and collagen bundles in the dermis. Accordingly, the anisotropy factors, displayed in Fig. $2 \mathrm{~b}$, are slightly lower at $60^{\circ} \mathrm{C}$. Similar to the scattering coefficients, reduced scattering coefficients presented in Fig. $2 \mathrm{c}$ demonstrate steeper gradient at $60^{\circ} \mathrm{C}$, as compared to those observed at 25 or $36^{\circ} \mathrm{C}$.

Confocal imaging. Reflectance confocal videos of mouse ear were recorded in vivo and used to monitor temperature dependent morphological changes as the temperature was increasing from $25^{\circ} \mathrm{C}$ to $60{ }^{\circ} \mathrm{C}$. Two image frames acquired at $25^{\circ} \mathrm{C}$ and $60^{\circ} \mathrm{C}$ are shown in Fig. 3a,b, respectively. Skin structures and appendages, such as hair follicles (solid arrows), and blood vessel (dashed arrows), can be seen on the background of dermal collagen in Fig. 3a. Highly scattering erythrocytes (dotted arrows) can be discerned flowing within a blood vessel. Corresponding video, presented in Supplementary Video S1, allows for a better visualization of the blood flow. The shaft of an adjacent hair follicle appears dark due to lack of melanin in albino mice. Figure $3 \mathrm{~b}$ shows the same region at a temperature of $60^{\circ} \mathrm{C}$. At this temperature, tissues coagulate and shrink. It has been shown that coagulation process is accompanied by collagen swelling, homogenization and collapse of the blood vessel walls, and destruction of the erythrocytes ${ }^{15}$. All these changes are evident in the image. Reflectance from swollen collagen increases, hair follicles shrink, and the blood vessel, present in Fig. 3a, disappears. The video showing morphological changes of the tissue during its heating from 25 to $60^{\circ} \mathrm{C}$ can be viewed in Supplementary Video S2.

\section{Discussion}

Clinical adoption and optimization of diagnostic, therapeutic, and surgical applications of light require understanding of its propagation and interaction with target tissues. Therefore, optical properties of biotissues, such as absorption coefficients $\left(\mu_{a}\right)$, scattering coefficients $\left(\mu_{s}\right)$, and anisotropy factors $(\mathrm{g})$, have been studied extensively in recent years ${ }^{29-37}$. Due to logistical challenges, most investigations of optical properties have been performed ex vivo $^{37-41}$. Alternatively, in the minority of studies, spatially resolved diffuse reflectance of remitted light was measured to determine absorption and reduced scattering coefficients using the diffusion approximation of light transport in turbid media ${ }^{24-27}$. To the best of our knowledge, this is the first comprehensive study that reports and quantifies temperature induced changes of tissue optical properties in vivo in the spectral range of 400-1650 nm using integrating sphere spectrophotometry and inverse Monte Carlo data processing. Still, several groups investigated temperature induced changes of skin, blood and water. For example, Helfmann et al. ${ }^{42}$, determined absorption, scattering, and anisotropy of oxygenated and deoxygenated blood using a double integrating sphere system and an Inverse Monte Carlo method. They report absorption peaks located at $415 \mathrm{~nm}, 540 \mathrm{~nm}$, and $575 \mathrm{~nm}$ for oxygenated blood, and $430 \mathrm{~nm}$ and $550 \mathrm{~nm}$ for deoxygenated blood. These spectral differences between oxygenated and deoxygenated blood match differences found between 25 and $60^{\circ} \mathrm{C}$ absorption spectra found in the present study. Jia et al. $^{43}$, measured the absorbance of blood in the spectral range of 500-650 nm while samples were heated to $60-80^{\circ} \mathrm{C}$. They reported an increased contribution from deoxyhemoglobin to absorbance measurements when heated to $60-80{ }^{\circ} \mathrm{C}$. Findings from both Helfmann et al. ${ }^{42}$, and Jia et al. ${ }^{43}$, confirm the deoxygenation of blood with increasing temperature found in the present study. Nilsson et al..$^{44}$, determined the optical properties of whole blood, heated to $25-55^{\circ} \mathrm{C}$, at $633 \mathrm{~nm}$. In agreement with our study, they found an increase in both scattering and absorption, as well as slight decrease of anisotropy factor of heated blood at $633 \mathrm{~nm}$. Barton et al. ${ }^{45}$, determined that pulsed laser illumination of hamster dorsal skin flap caused hemoglobin deoxygenation, blood coagulation, as well as blood vessel constriction due to tissue heating. They have also noted significant increase of tissue absorption coefficients. These results are concordant with our findings. Barton et al. ${ }^{45}$ also reported the formation of methemoglobin after laser illumination. Methemoglobin was not detected in the present study at $60^{\circ} \mathrm{C}$. This discrepancy may be explained by the discovery of Jia et al..$^{43}$, that measurable amounts of methemoglobin start to form as blood temperatures reach $70^{\circ} \mathrm{C}$.

Laufer et al. ${ }^{17}$, measured the temperature induced changes in absorption and reduced scattering using an integrating sphere system and an Inverse Monte Carlo method. They report an increase in reduced scattering found in ex vivo human dermis as tissue temperature increased from 25 to $40{ }^{\circ} \mathrm{C}$ in the $600-1000 \mathrm{~nm}$ spectral range. This increase in reduced scattering agrees with the findings in the present study. Laufer et al. ${ }^{17}$, reported no significant changes in tissue absorption in this spectral range. Similarly, our study revealed that temperature induced changes in absorption coefficients in the spectral range between 600 and $1000 \mathrm{~nm}$ are minimal.

Several studies investigated temperature induced blue shifts of water absorption ${ }^{46-52}$. In particular, Collins ${ }^{46}$ measured the absorbance of water samples between 0 and $95^{\circ} \mathrm{C}$ and reported a $40 \mathrm{~nm}$ and a $20 \mathrm{~nm}$ blue shift of the absorption peaks in the vicinity of $1200 \mathrm{~nm}$ and $1450 \mathrm{~nm}$, respectively. These shifts in the absorption spectra qualitatively agree with those found in this present study. However, Collins ${ }^{46}$ did not observe an increase 


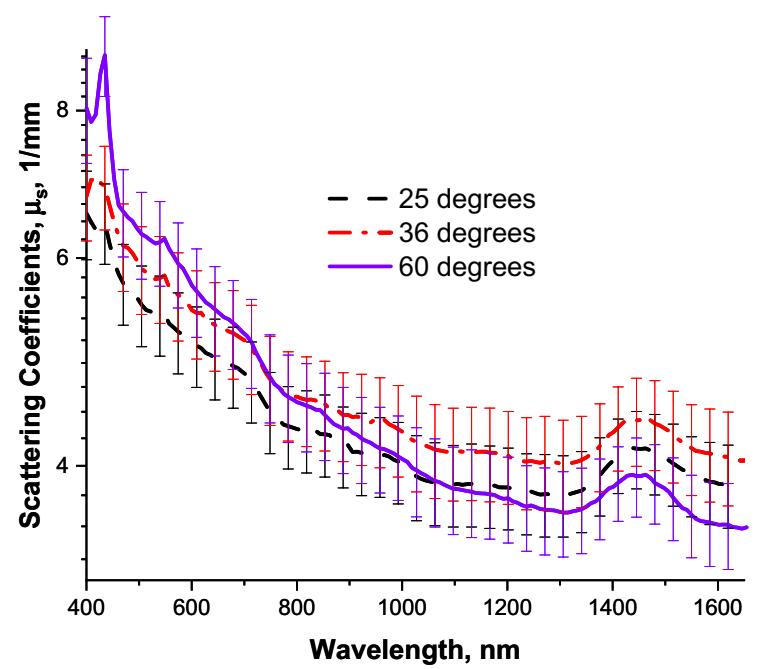

(a)

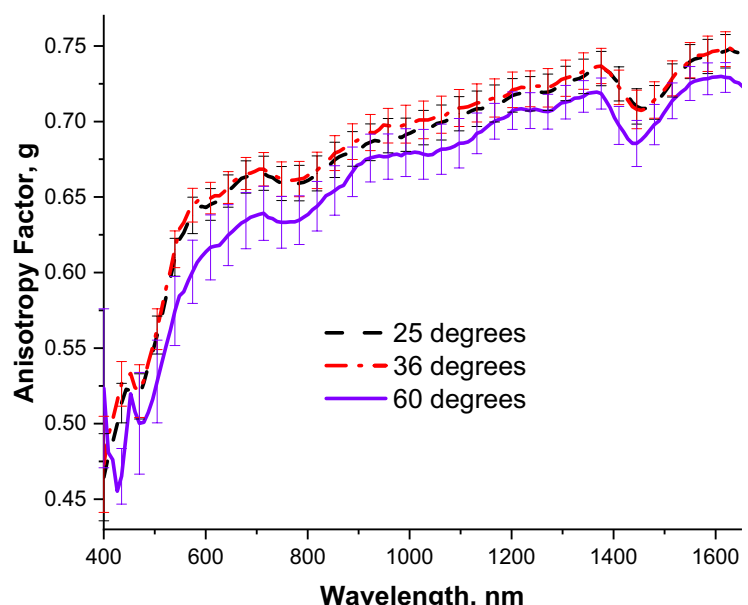

(b)

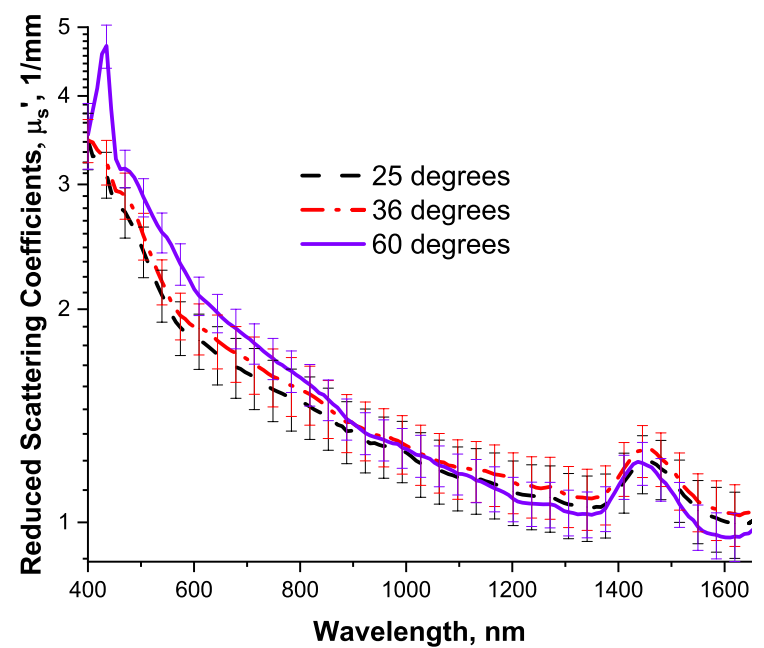

(c)

Figure 2. (a) Scattering coefficients between $400-1650 \mathrm{~nm}$. (b) Anisotropy factors between $400-1650 \mathrm{~nm}$. (c) Reduced scattering coefficients between $400-1650 \mathrm{~nm}$. Dashes $-25^{\circ} \mathrm{C}$. Dashes and dots $-36{ }^{\circ} \mathrm{C}$. Solid line$60^{\circ} \mathrm{C}$. Bars-standard errors. 


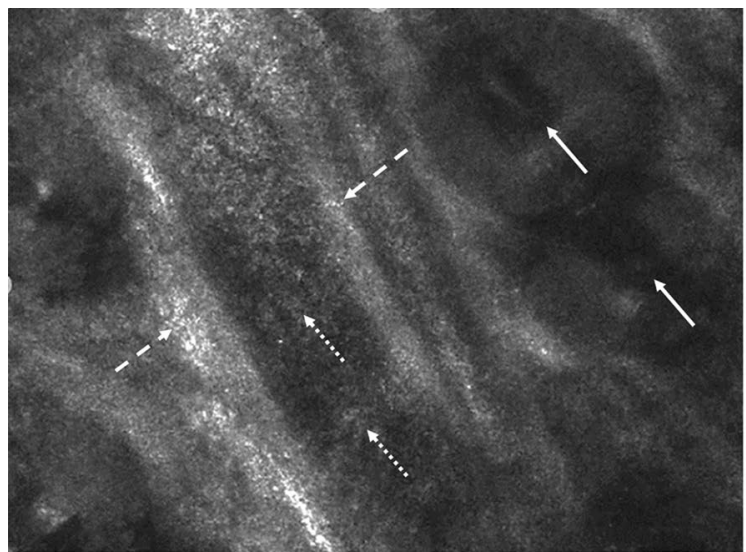

(a)

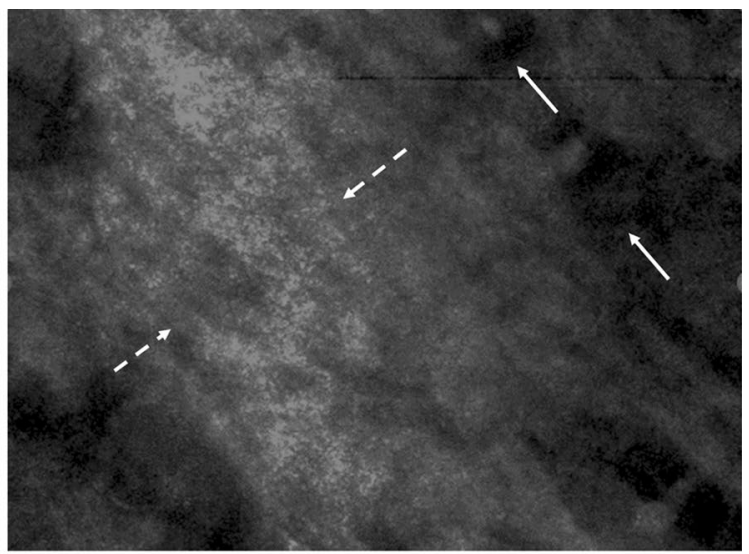

(b)

Figure 3. Representative reflectance confocal images of in vivo mouse ear tissue at (a) $25^{\circ} \mathrm{C}$ and (b) $60{ }^{\circ} \mathrm{C}$. Confocal videos of in vivo mouse ear tissue at $25^{\circ} \mathrm{C}$, and heated to $60^{\circ} \mathrm{C}$, are shown in Supplemental Videos S1 and S2, respectively. Dashed arrows and dotted arrows point to a vascular wall and erythrocytes inside the vessel, respectively. Solid arrows points to a hair follicle. FOV $=750 \mu \mathrm{m} \times 560 \mu \mathrm{m}$.

in amplitude of the $1450 \mathrm{~nm}$ peak found in our study. This increase can be explained by temperature induced edema, which does not occur in pure water samples.

Overall, the comparison of the results obtained in this study shows that our data are in qualitative agreement with the trends reported in the literature for ex vivo and in vivo tissues, when the latter are available. The discrepancies as well as the variations within the values reported in the literature are most probably due to the variations in experimental conditions, as well as differences in theoretical models and tissue treatment techniques employed in the studies. In conclusion, we have investigated the temperature induced changes of the mouse ear skin optical properties in vivo between 400 and $1650 \mathrm{~nm}$ in the temperature range between $25^{\circ} \mathrm{C}$ and $60{ }^{\circ} \mathrm{C}$. Our results demonstrate that the major differences in absorption are caused by deoxygenation of blood and heating of water, while the major differences in scattering are caused by blood and collagen coagulation. Reflectance confocal microscopy confirms these findings. Imaging reveals tissue shrinkage during its heating from 25 to $60^{\circ} \mathrm{C}$. This shrinkage leads to the increased concentration of chromophores and explains significant rise of absorption coefficients at $60^{\circ} \mathrm{C}$ as compared to $25^{\circ} \mathrm{C}$ and $36^{\circ} \mathrm{C}$. The results of this study may provide a reliable foundation for dosimetry of therapeutic and diagnostic clinical procedures.

\section{Methods}

All methods were carried out in accordance with relevant guidelines and regulations.

Animal handling. All procedures involving animals were performed under a protocol approved by the Massachusetts General Hospital Subcommittee on Research Animal Care and followed the ARRIVE guidelines for reporting animal experiments. The BALB/c mice used in this study were obtained from Charles River Breeding Laboratory (Wilmington, MA).

Prior to the spectroscopic experiments, anesthesia was induced using an intraperitoneal injection of ketamine-xylazine mix (10:1) at a dose of $1 \mu \mathrm{L} / \mathrm{g}$ body weight. The anesthesia was maintained for up to $30 \mathrm{~min}$, providing adequate time to perform the measurements. Mice were sacrificed immediately following the final measurements.

Integrating sphere spectrophotometry. An in-house built single integrating sphere spectrophotometer, described in detail elsewhere ${ }^{33}$, was used for acquiring total transmittance, diffuse transmittance, and diffuse reflectance over the spectral range of $400-1650 \mathrm{~nm}$. Spectroscopic measurements were performed at $25^{\circ} \mathrm{C}$, $36^{\circ} \mathrm{C}$, and $60^{\circ} \mathrm{C}$. A halogen lamp (HL-2000, 360-2000 nm, Ocean Optics, Dunedin, FL) was used as the light source. Intensity fluctuations of the lamp did not exceed $0.1 \%$ over $6 \mathrm{~h}$. Two grating spectrophotometers, an HR2000 spectrometer (Ocean Optics, Dunedin, FL) and an EPP2000-NIR InGaAs spectrometer (StellarNet, Tampa, FL) simultaneously attached to the two auxiliary ports of the integrating sphere (4P-GPS-033-SL, Labsphere, North Sutton, NH) were used for measuring spectral responses in the 400-980 nm and the 900-1650 nm range, respectively.

For total and diffuse transmittance measurements, light emitted from a halogen lamp was focused on mouse ears that were attached to the entrance port of the integrating sphere. Transmittance through air was used as reference. The diameter of the focused beam was $1.9 \mathrm{~mm}$ and the diameter of the entrance port was $5 \mathrm{~mm}$. For measuring total transmittance, the exit port of the integrating sphere was closed. For measuring diffuse transmittance, the exit port was open to allow un-scattered light to escape. Collimated transmittance of the mouse ear was calculated by subtracting diffuse transmittance from the total transmittance signal for each wavelength of the spectral range investigated. 


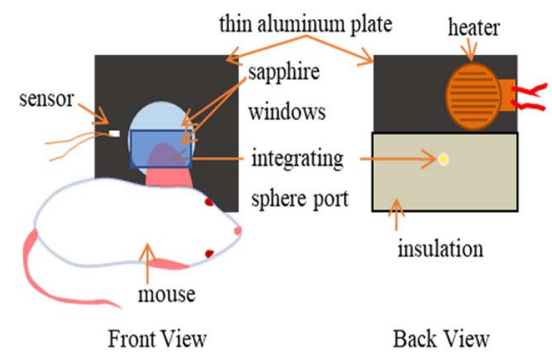

(a)

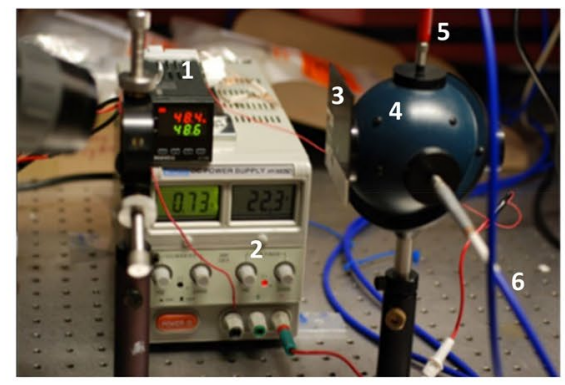

(b)

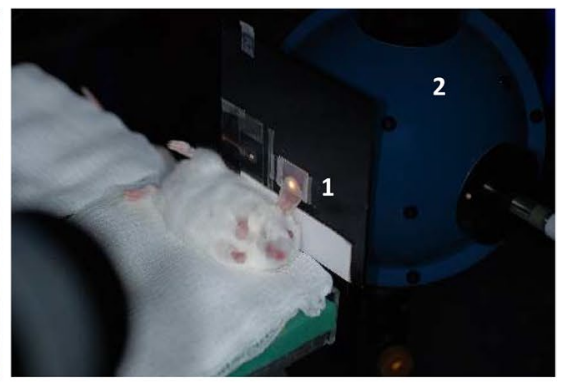

(c)

Figure 4. Lay-out of the integrating sphere experiments. (a) Diagram of the heating apparatus that was used to heat and maintain the desired tissue temperature while spectroscopic measurements were performed. Insulation between the aluminum plate and the integrating sphere, as well as between the aluminum plate and the mouse body prevented unnecessary heating. (b) Picture of integrating sphere system with heating apparatus. Temperature controller (1) was attached to a power supply (2) and aluminum plate (3). Controller (1) triggered external power for heating or cooling. Aluminum plate was attached to the sample port of the integrating sphere (4). Light collected by the integrating sphere passed through two optical fibers (5 and 6) coupled to the visible and NIR spectrometers. (c) Picture of total transmittance data acquisition. The mouse ear, sandwiched between two sapphire windows attached to the aluminum plate (1), was heated by the heater and the temperature was controlled by the temperature controller. Light transmitted through the ear was collected by the integrating sphere (2).

For diffuse reflectance measurements, light was focused on the mouse ears attached to the exit port of the integrating sphere. A 99\% spectralon diffuse reflectance standard (Labsphere Inc., North Sutton, NH) was used as a reference. The focal spot size was $1.9 \mathrm{~mm}$, the diameter of the exit port was $5 \mathrm{~mm}$, and the entrance port of the integrating sphere had a diameter of $25.4 \mathrm{~mm}$.

Data processing technique. An inverse Monte Carlo algorithm, described in detail previously ${ }^{53}$, was used to determine the optical properties from the measured quantities. The Monte Carlo (MC) technique took into account the exact geometrical and optical parameters of the experimental arrangement, the three-layer structure of the object under investigation (sapphire glass-mouse ear-sapphire glass) and losses of light at the edges of the ear. The MC technique was incorporated as a forward procedure into quasi-Newton inverse algorithm. The inverse algorithm employed Broyden update formula to reduce the number of the forward model calls and the "trust region" approach to achieve proximity of the solution even when the initial approximation was poor ${ }^{54}$. The inverse technique allowed determination of absorption coefficients, scattering coefficients and anisotropy factors from the measurements of total transmittance, collimated transmittance, and diffuse reflectance, while parameters of the phase function were pre-set. The anisotropy factors were determined under the assumption of the Henyey-Greenstein scattering phase function ${ }^{55}$.

Temperature control system. The temperature control system is depicted in Fig. 4a. Mouse ears were sandwiched between two sapphire windows and placed on top of an aluminum plate with the hole of the size of the entrance / exit port of the integrating sphere (diameter of $5 \mathrm{~mm}$ ). This hole in the aluminum plate enabled light to pass through and enter the integrating sphere. A heater (HK5541R30, Minco, Minneapolis, MN) was attached to the aluminum plate and powered by an external power supply (Tekpower HY3005D, Tekpower, Montclair, CA). The heater and power supply were connected to a temperature control unit (CT16A2080-948, Minco, Minneapolis, MN), and a temperature sensor was attached to the aluminum plate. The aluminum plate reached the desired temperature within $30 \mathrm{~s}$ of heating and the desired temperature was maintained within $\pm 0.1^{\circ} \mathrm{C}$. Photographs of the integrating sphere system with heating apparatus are displayed in Fig. $4 \mathrm{~b}, \mathrm{c}$. In addition, the temperature was concurrently monitored using a thermal camera (ThermaCAM PM390, FLIR Systems, Wilsonville, OR). Temperature settings of $25^{\circ} \mathrm{C}, 36^{\circ} \mathrm{C}$, and $60^{\circ} \mathrm{C}$ were used during collection of the total transmittance, diffuse transmittance, and diffuse reflectance data.

Confocal microscopy. To reveal structural and functional changes in the mouse ear during heating, we monitored the heating process using a commercial confocal microscope (Vivascope 2000, Lucid Inc., Rochester, New York) (Fig. 5a). A detailed description of the confocal system is available in a previous publication ${ }^{56}$. In short, illumination was provided by $830 \mathrm{~nm}$ diode laser (Micro Laser Systems Inc., Garden Grove, CA). Laser light was focused onto the sample by a 20x/NA 0.75 water-immersion objective lens (Nikon Inc., Tokyo, Japan). The imager provided lateral and axial resolution of $1.5 \mu \mathrm{m}$ and $5 \mu \mathrm{m}$, respectively. The imaging depth was approximately $100 \mu \mathrm{m}$ with a field of view of $800 \times 600 \mu \mathrm{m}^{2}$. The mice were placed supine on the inverted sample stage (Fig. 5b). Confocal images and videos were acquired as mouse ears were heated from $25^{\circ} \mathrm{C}$ to $60^{\circ} \mathrm{C}$ 


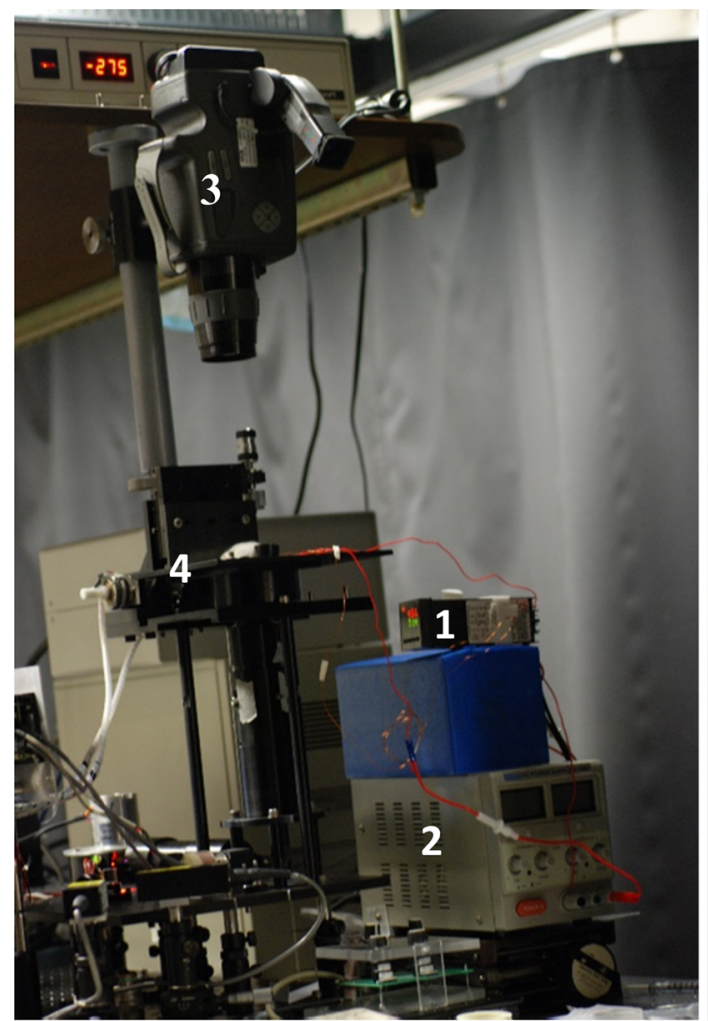

(a)

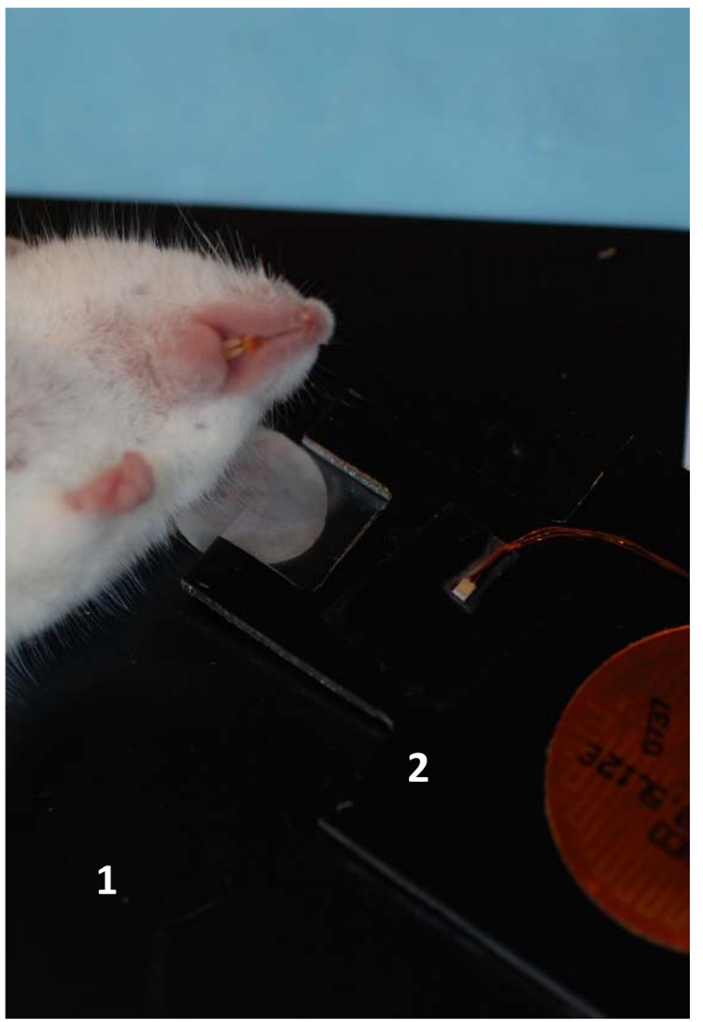

(b)

Figure 5. Imaging experiments lay-out. (a) Reflectance confocal microscope with heating apparatus and thermal camera. External temperature controller (1) and power supply (2) were used to heat and maintain the desired tissue temperature. Thermal camera (3) was positioned above the sample stage (4) to provide independent temperature monitoring. (b) Picture of mouse ear positioning on the sample stage (1) of the confocal microscopy system. Ear tissue was heated using the same heating apparatus (2) as for the integrating sphere measurements.

using the temperature control system described above. For validation purposes, temperature was concurrently monitored using a thermal camera (ThermaCAM PM390, FLIR Systems, Wilsonville, OR).

Statistical analysis. The optical data were evaluated statistically to obtain least squares estimates of mean gradient (slopes of scattering and reduced scattering) or shifts of absorption maxima, along with corresponding standard errors, for each temperature group. A mixed effects model ${ }^{57}$ was used to assess differences between gradients and extremum shifts observed at $25^{\circ} \mathrm{C} / 60^{\circ} \mathrm{C}$ and $36{ }^{\circ} \mathrm{C} / 60^{\circ} \mathrm{C}$ with $P \leq 0.05$ considered significant.

Ethical approval. All procedures involving animals were performed under a protocol approved by the Massachusetts General Hospital Subcommittee on Research Animal Care. All procedures involving animals were reported following the ARRIVE guidelines.

\section{Data availability}

Datasets related to this article can be obtained from the corresponding author.

Received: 7 November 2020; Accepted: 17 December 2020

Published online: 12 January 2021

\section{References}

1. Chen, Q. et al. Photothermal therapy with immune-adjuvant nanoparticles together with checkpoint blockade for effective cancer immunotherapy. Nat. Commun. 7, 13193. https://doi.org/10.1038/ncomms13193 (2016).

2. Kim, H., Jo, G. \& Chang, J. H. Ultrasound-assisted photothermal therapy and real-time treatment monitoring. Biomed. Opt. Express. 9, 332364. https://doi.org/10.1364/BOE.9.004472 (2018).

3. Nomura, S. et al. Thermal sensor circuit using thermography for temperature-controlled laser hyperthermia. J. Sens. 2017, 3738046. https://doi.org/10.1155/2017/3738046 (2017).

4. Quintanilla, M. et al. Thermal monitoring during photothermia: hybrid probes for simultaneous plasmonic heating and nearinfrared optical nanothermometry. Theranostics 9, 7298-7312 (2019). 
5. Saccomandi, P., Schena, E. \& Silvestri, S. Techniques for temperature monitoring during laser-induced thermo-therapy: an overview. Int. J. Hyperth. 29(7), 609-619. https://doi.org/10.3109/02656736.2013.832411 (2013).

6. Tosi, D. et al. Fiber-optic chirped FBG for distributed thermal monitoring of ex-vivo radiofrequency ablation of liver. Biomed. Opt. Express. 5, 1799. https://doi.org/10.1364/BOE.5.001799 (2014).

7. Moy, W. J., Ma, G., Kelly, K. M. \& Choi, B. Hemoporfin-mediated photodynamic therapy on normal vasculature: implications for phototherapy of port-wine stain birthmarks. J. Clin. Transl. Res. 2(3), 107-111 (2016).

8. Sun, J. et al. Recent progress in metal-based nanoparticles mediated photodynamic therapy. Molecules 23, 1704. https://doi. org/10.3390/molecules23071704 (2018).

9. Salehpour, F. et al. Brain photobiomodulation therapy: a narrative review. Mol. Neurobiol. 55(8), 6601-6636. https://doi.org/10.1007/ s12035-017-0852-4 (2018).

10. Hoppe, C. et al. Laser interstitial thermotherapy (LiTT) in epilepsy surgery. Seizure. 48, 45-52. https://doi.org/10.1016/j.seizu re.2017.04.002 (2017).

11. Alagha, H. Z. \& Gülsoy, M. Photothermal ablation of liver tissue with 1940-nm thulium fiber laser: an ex vivo study on lamb liver. J. Biomed. Opt. 21(1), 015007. https://doi.org/10.1117/1.JBO.21.1.015007 (2016).

12. Vignali, L., Solinas, E. \& Emanuele, E. Research and clinical applications of optical coherence tomography in invasive cardiology: a review. Curr. Cardiol. Rev. 10, 369-376 (2014).

13. Schwarzmaier, H. J. et al. Treatment planning for MRI-guided laser-induced interstitial thermotherapy of brain tumors-the role of blood perfusion. JMRI. 8(1), 121-127. https://doi.org/10.1002/jmri.1880080124 (1998).

14. Yanina, I. Y., Lazareva, E. N., Bashkatov, A. N. \& Tuchin, V. V. Refractive properties of human adipose tissue at hyperthermic temperatures. In 2018 International Conference Laser Optics (ICLO) 517-517. https://doi.org/10.1109/LO.2018.8435657 (2018).

15. Yaroslavsky, A. N. et al. Optical properties of selected native and coagulated human brain tissues in vitro in the visible and near infrared spectral range. Phys. Med. Biol. 47(12), 2059-2073 (2002).

16. Yu, T. et al. Elevated-temperature-induced acceleration of PACT clearing process of mouse brain tissue. Sci. Rep. 7, 38848. https ://doi.org/10.1038/srep38848 (2017).

17. Laufer, J., Simpson, R., Kohl, M., Essenpreis, M. \& Cope, M. Effect of temperature on the optical properties of ex vivo human dermis and subdermis. Phys. Med. Biol. 43, 2479-2489 (1998).

18. Nguyen, J. Q. et al. Spatial frequency domain imaging of burn wounds in a preclinical model of graded burn severity. J. Biomed. Opt. 18(6), 066010. https://doi.org/10.1117/1.JBO.18.6.066010 (2013).

19. Salomatina, E. \& Yaroslavsky, A. N. Evaluation of the in vivo and ex vivo optical properties in a mouse ear model. Phys. Med. Biol. 53, 2797-2807 (2008).

20. Skinner, M. G. et al. Changes in optical properties of ex vivo rat prostate due to heating. Phys. Med. Biol. 45, 1375-1386 (2000).

21. Joseph, F. K. et al. Key features in the optical properties of tissue during and after radiofrequency ablation. In Proceedings of SPIE 11216. Multiscale Imaging and Spectroscopy, 112160H. https://doi.org/10.1117/12.2546042 (2020).

22. Nagarajan, V. K., Gogineni, V. R., White, S. B. \& Yu, B. Real time evaluation of tissue optical properties during thermal ablation of ex vivo liver tissues. Int. J. Hyperther. 35(1), 176-182 (2018).

23. Nagarajan, V. K., Ward, J. M. \& Yu, B. Association of liver tissue optical properties and thermal damage. Lasers Surg. Med. 52(8), 23209. https://doi.org/10.1002/lsm.23209 (2019).

24. Chen, Q. et al. Changes in in vivo optical properties and light distributions in normal canine prostate during photodynamic therapy. Radiat. Res. 147, 86-91 (1997).

25. Hayward, J. E., Bruulsema, J. T., Patterson, M. S. \& Essenpreis, M. In vivo temperature dependence of human skin optical properties in the NIR. Biomed. Opt. OSA Tech. Digest. https://doi.org/10.1364/BIO.1999.ATuA3 (1999).

26. Ouyang, Q., Zhu, D., Luo, Q., Gong, H. \& Luo, Q. Modulation of temperature on optical properties of rat skin in vivo. In Proceedings of SPIE 6534, Fifth International Conference on Photonics and Imaging in Biology and Medicine, 65343I. https://doi. org/10.1117/12.741499 (2007)

27. Yeh, S. J. et al. Temperature dependence of optical properties of in-vivo human skin. In Proceedings of SPIE 4250, Optical Tomography and Spectroscopy of Tissue IV, 4250. https://doi.org/10.1117/12.434482 (2011).

28. Lei, H. et al. The effects of ketamine-xylazine anesthesia on cerebral blood flow and oxygenation observed using nuclear magnetic resonance perfusion imaging and electron paramagnetic resonance oximetry. Brain Res. 913, 174-179 (2001).

29. Hassaninia, I., Bostanabad, R., Chen, W. \& Mohseni, H. Characterization of the optical properties of turbid media by supervised learning of scattering patterns. Sci. Rep. 7, 15259. https://doi.org/10.1038/s41598-017-15601-4 (2017).

30. Jacques, S. L. Origins of tissue optical properties in the UVA, visible, and NIR regions. OSA TOPS Adv. Opt. Imaging Photon Migr. 2, 364-371 (1996).

31. Poulon, F. et al. Optical properties, spectral, and lifetime measurements of central nervous system tumors in humans. Sci. Rep. 7, 13995. https://doi.org/10.1038/s41598-017-14381-1 (2017).

32. Sabino, C. P. et al. The optical properties of mouse skin in the visible and near infrared spectral regions. J. Photochem. Photobiol. B 160, 72-78 (2016).

33. Salomatina, E., Jiang, B., Novak, J. \& Yaroslavsky, A. N. Optical properties of normal and cancerous human skin in the visible and near-infrared spectral range. J. Biomed. Opt. 11(6), 064026. https://doi.org/10.1117/1.2398928 (2006).

34. Yamaguchi, S. et al. Brain tumor imaging of rat fresh tissue using terahertz spectroscopy. Sci. Rep. 6, 30124. https://doi.org/10.1038/ srep30124 (2016).

35. Yaroslavsky, A. N., Yaroslavsky, I. V., Goldbach, T. \& Schwarzmaier, H. J. Optical properties of blood in the near-infrared spectral range. In Proceedings of SPIE. Optical Diagnostics of Living Cells and Biofluids, 2678. https://doi.org/10.1117/12.239516 (1996).

36. Yaroslavsky, A. N., Yaroslavsky, I. V., Goldbach. T. \& Schwarzmaier, H. J. Different phase-function approximations to determine optical properties of blood: a comparison. In Proceedings of SPIE. Optical Diagnostics of Biological Fluids and Advanced Techniques in Analytical Cytology, 2982. https://doi.org/10.1117/12.273654 (1997).

37. Agah, R., Gandjbakhche, A. H., Motamedi, M., Nossal, R. \& Bonner, R. F. Dynamics of temperature dependent optical properties of tissue: dependence on thermally induced alteration. IEEE Trans. Biomed. Eng. 43, 839-846 (1996).

38. Gnanadesigan, M. et al. Effect of temperature and fixation on the optical properties of atherosclerotic tissue: a validation study of an ex-vivo whole heart cadaveric model. Biomed. Opt. Express 5(4), 1038-1049 (2014).

39. Schwarzmaier, H. J. et al. Optical properties of native and coagulated human brain structures. In Proceedings of the SPIE, Lasers in Surgery: Advanced Characterization, Therapeutics, and Systems VII, 2970. https://doi.org/10.1117/12.275082 (1997).

40. Schwarzmaier, H. J. et al. Changes in the optical properties of laser-coagulated and thermally coagulated bovine myocardium. In Proceedings of the SPIE. Laser-Tissue Interaction IX, 3254. https://doi.org/10.1117/12.308186 (1998).

41. Simpson, C. R., Kohl, M., Essenpreis, M. \& Cope, M. Near-infrared optical properties of ex vivo human skin and subcutaneous tissues measured using the Monte Carlo inversion technique. Phys. Med. Biol. 43, 2465-2478 (1998).

42. Helfmann, M. F. J., Netz, U. \& Meinke, M. Influence of oxygen saturation on the optical scattering properties of human red blood cells in the spectral range 250 to $2000 \mathrm{~nm}$. J. Biomed. Opt. 14(3), 034001. https://doi.org/10.1117/1.3127200 (2009).

43. Jia, H., Chen, B. \& Li, D. Dynamic optical absorption characteristics of blood after slow and fast heating. Lasers Med. Sci. 32, 513-525 (2017).

44. Nilsson, A. M. K., Lucassen, G. W., Verkruysse, W., Andersson-Engels, S. \& Gemert, M. J. C. Changes in optical properties of human whole blood in vitro due to slow heating. Photochem. Photobiol. 65(2), 366-373 (1997). 
45. Barton, J. K., Frangineas, G., Pummer, H. \& Black, J. F. Cooperative phenomena in two-pulse, two-color laser photocoagulation of cutaneous blood vessels. Photochem. Photobiol. 73(6), 642-650 (2001).

46. Collins, J. R. Change in the infra-red absorption spectrum of water with temperature. Phys. Rev. 26(6), 771-779 (1925).

47. Buiteveld, H., Hakvoort, J. M. H. \& Donze, M. The optical properties of pure water. Proc. SPIE Ocean Opt. XII 2258, 1994. https ://doi.org/10.1117/12.1900060 (1994).

48. Jansen, E. D., van Leeuwen, T. G., Motamedi, M., Borst, C. \& Welch, A. J. Temperature dependence of the absorption coefficient of water for midinfrared laser radiation. Lasers Surg. Med. 14, 258-268 (1994).

49. Langford, V. S., McKinley, A. J. \& Quickenden, T. I. Temperature dependence of the visible-near-infrared absorption spectrum of liquid water. J. Phys. Chem. A 105, 8916-8921 (2001).

50. Lange, B. I., Brendel, T. \& Hüttmann, G. Temperature dependence of light absorption in water at holmium and thulium laser wavelengths. Appl. Opt. 41(27), 5797-5803 (2002).

51. Jensen, P. S., Bak, J. \& Andersson-Engels, S. Influence of temperature on water and aqueous glucose absorption spectra in the near- and mid-infrared regions at physiologically relevant temperatures. Appl. Spectrosc. 57(1), 28-36 (2003).

52. Otal, E. H., Iñón, F. A. \& Andrade, F. J. Monitoring the temperature of dilute aqueous solutions using near-infrared water absorption. Appl. Spectrosc. 57(6), 661-666 (2003).

53. Yaroslavsky, I. V., Yaroslavsky, A. N., Goldbach, T. \& Schwarzmaier, H. J. Inverse hybrid technique for determining the optical properties of turbid media from integrating-sphere measurements. Appl. Opt. 35(34), 6797-6809 (1996).

54. Dennis, J. E. \& Schnabel, R. B. Numerical Methods for Unconstrained Optimization and Nonlinear Equations (Prentice-Hall, Upper Saddle River, 1983).

55. Henyey, L. G. \& Greenstein, J. L. Diffuse radiation in the Galaxy. Astrophys. J. 93, 70-83 (1941).

56. Yaroslavsky, A. N., Barbosa, J. G., Neel, V., DiMarzio, C. A. \& Anderson, R. R. Combining multispectral polarized light imaging and confocal microscopy for localization of nonmelanoma skin cancer. J. Biomed. Opt. 10(1), 014011. https://doi.org/10.1117/1.18541 73 (2005).

57. Demidenko, E. Mixed Models: Theory and Applications with R (Wiley, New York, 2013).

\section{Acknowledgements}

We would like to thank Mauricio Cordero, M.S., and Michael Hamblin, Ph.D. from the Wellman Center for Photomedicine at Massachusetts General Hospital for technical support and help with animal handling.

\section{Author contributions}

Conception and Design: A.Y. Development of Methodology: A.Y. Data Acquisition and Management: E.S., A.Y. Data Analysis (computational and statistical analysis) and Interpretation: T.I., A.Y., A.M., P.J. Writing, Review, and/or Revision of the Manuscript: A.Y., P.J., T.I., A.M.

\section{Competing interests}

The authors declare no competing interests.

\section{Additional information}

Supplementary Information The online version contains supplementary material available at https://doi. org/10.1038/s41598-020-80254-9.

Correspondence and requests for materials should be addressed to A.N.Y.

Reprints and permissions information is available at www.nature.com/reprints.

Publisher's note Springer Nature remains neutral with regard to jurisdictional claims in published maps and institutional affiliations.

(c) (i) Open Access This article is licensed under a Creative Commons Attribution 4.0 International License, which permits use, sharing, adaptation, distribution and reproduction in any medium or format, as long as you give appropriate credit to the original author(s) and the source, provide a link to the Creative Commons licence, and indicate if changes were made. The images or other third party material in this article are included in the article's Creative Commons licence, unless indicated otherwise in a credit line to the material. If material is not included in the article's Creative Commons licence and your intended use is not permitted by statutory regulation or exceeds the permitted use, you will need to obtain permission directly from the copyright holder. To view a copy of this licence, visit http://creativecommons.org/licenses/by/4.0/.

(C) The Author(s) 2021 